\title{
A vivência da gravidez e da maternidade de prostitutas
}

\author{
Márcia Cristina Teffa de Siqueira Peres* \\ Maria Lúcia Castilho Romera**
}

\section{RESUMO}

Trata-se do relato de uma investigação sobre os sentidos e significados, manifestos e latentes, compreendidos na motivação e na ação de engravidar de prostitutas, bem como de sua percepção de maternidade.

Para isso, foram utilizadas técnicas de entrevista e observação. Foram entrevistadas três prostitutas grávidas e quatro prostitutes que já haviam estado grávidas. Os discursos foram submetidos à análise através do método interpretativo/indiciário. Constatou-se uma grande dificuldade por parte das prostitutas no exercício das funções relacionadas à maternidade. Tal fato encontra explicação na estrutura mental infantil dessas mulheres, sem falar na sua escassez de recursos de simbolização. O sig-

\footnotetext{
* Ginecologista e Obstetra. Especialista em Orientação Sexual pela Universidade Federal de Uberlândia.

** Psicóloga. Doutora em Psicologia pela USP Professora Adjunto da Universidade Federal de Uberlândia. Psicanalista do Instituto da SBPSP.

Recebido em 15.11 .98

Aprovado em 30.11 .98
} 
nificado de corpo para elas parece não transcender a dimensão do orgânico. É visto como um objeto, uma mercadoria, um instrumento de troca.

A não convivência com um modelo familiar tradicional parece contribuir, no futuro, para o não estabelecimento do vínculo mãe/filho, justificando a entrega dos filhos aos cuidados de terceiros.

\section{INTRODUÇÃO}

A prostituição, desde a antigüidade, sempre esteve coberta por um manto de preconceito e discriminação. No imaginário social a idéia que se tem desse ofício é aquela vinculada à aquisição de doenças sexualmente transmissíveis, às perversões sexuais e à criminalidade. A prostituição continua sendo vista como uma ameaça tanto para a família, como para a sociedade. Paradoxalmente, parece garantir a manutenção do "status quo" (FOUCAULT, 1984).

Pouco ou quase nada se discute sobre a história de vida dessas profissionais que no dia a dia se vendem como mercadorias. Geralmente, fechamos os olhos ou ignoramos o lado trágico da história: os maltrates da infância, a ausência de figuras parentais participativas, o abandono, a miséria, e a ignorância.

Essa leitura preconceituosa da condição da prostituta encontra sustentação na tradição Judáico-Cristã que estabelece dois padrões de feminino: a Virgem Maria, mãe, pura e santa e Eva, a pecadora que sucumbiu à tentação e provou do fruto proibido. Eva não é sequer lembrada como a mãe da humanidade. Prevalece a imagem da mulher imoral e corrupta. Da mesma forma, o papel de mãe da prostituta é dificilmente mencionado. Desconhece-se qual seria sua motivação para engravidar, sua percepção do corpo grávida, os sentimentos que a perpassam nos nove meses de gestação, enfim que sentido teria a maternidade para sua vida.

$\mathrm{Na}$ literatura, são raras as estatísticas sobre o número de mulheres que engravidam trabalhando no meretrício e não foi encontrado nenhum trabalho que estabelecesse uma articulação entre prostituição e gravidez/maternidade, porém pelos resultados de alguns poucos estudos e através de conversas informais preliminares entre algumas prostitutas e a autora, ocorridas em casas de prostituição, foi possível se ter uma idéia de que esse número deva ser significativo. 
BEDONE et al. (1987), num grupo de 100 prostitutas, encontraram apenas $10 \%$ de nuligestas ${ }^{1}$ e quanto ao número de partos, observaram que $79 \%$ tiveram um ou mais partos.

CAROLINO (1980), em sua dissertação de mestrado investigou 114 prostitutas e verificou que $86 \%$ dessa população já havia engravidado.

DEISHER et al. (1991) estudaram 54 adolescentes engajadas na prostituição com idade entre 14 e 20 anos e encontraram em sua amostra $46 \%$ de primíparas e $54 \%$ de multíparas.

É plausível que os resultados estatísticos devam ser olhados ou considerados com alguma reserva, visto que as pessoas que exercem essa atividade, o fazem de forma clandestina, muitas vezes levando uma vida dupla: a profissional e a familiar.

Não foram encontrados dados revelando a idade da prostituta quando ela engravida pela primeira vez, porém BEDONE et al. (1987) citam 5 casos em que as mulheres ingressaram na prostituição por terem sido expulsas de casa quando ficaram grávidas. Possivelmente tal fato tenha ocorrido na fase da adolescência.

Outra questão a ser levantada seria o uso ou não de métodos contraceptivos. No mesmo estudo de BEDONE et al., anteriormente citado, obteve-se a informação de que menos da metade das mulheres estavam protegidas com métodos anticoncepcionais eficientes; aproximadamente $24,4 \%$ delas não usavam nenhum método e $29,9 \%$ estavam grávidas por ocasião das entrevistas.

CAROLINO (1980) relata que a maioria da amostra investigada $(59,3 \%)$ não se preocupava com o controle da natalidade. Neste mesmo estudo, a autora encontrou um alto índice de abortamento, sobrepujando a interrupção espontânea sobre a provocada. BEDONE et al. (1987) referem que 30 mulheres relataram ter provocado aborto mais de uma vez, totalizando 67 abortos, (equivalente a mais de 2 abortos por mulher) o que não deixa de ser um número significativo.

Não foi encontrado na literatura qualquer menção sobre a procura dessas pessoas por serviços de assistência pré-natal. Se o fazem, presumivelmente, não confidenciam sua condição. DEISHER et al. (1991) consideram ser adequado um mínimo de nove visitas médicas, iniciando-se no $1^{\circ}$ trimestre, para prostitutas adolescentes darem a luz à crianças a termo. Esses autores descrevem ainda, fatores de risco para a gravidez, tais como: abuso de drogas, violência, doenças sexualmente transmissíveis, deficiên-

1. Nuligesta: que nunca engravidou. 
cias nos cuidados médicos e má nutrição. Demonstram uma correlação entre complicações maternas e prognósticos ruins para os recém nascidos, quando tais fatores de risco encontram-se presentes.

Alguns estudos apontam para uma separação entre mãe e filho logo após o nascimento, ficando o mesmo aos cuidados de outrem, comumente um parente. Apesar disso, pode existir um vínculo efetivo entre as partes, com a mãe preocupando-se em prover as necessidades materiais do filho. (BEDONE et al., 1987; CAROLINO, 1980).

O interesse pelo tema surgiu após a constatação de que apesar da condição de maternidade parecer incompatibilizar-se com a profissão de prostituta, a gravidez entre elas acontece com frequiência. Além disso percebemos nesse grupo uma despreocupação com relação à contracepção, uma elevada incidência de abortamento, a não participação nas consultas de pré-natal e, depois do parto, a entrega dos filhos aos cuidados de outras pessoas.

O propósito deste estudo foi investigar qual seria a motivação da mulher prostituta para engravidar bem como sua percepção e representação de gravidez/maternidade. Com esse intuito procuramos detectar aspectos do contexto de vida pregressa e atual destas mulheres nos aspectos bio-psico-(familiar)-social que nos ajudassem na compreensão do fenômeno estudado. Outro objetivo foi encontrar subsídios para a implantação de programas de caráter assistencial em âmbito psicológico e de saúde pública que se identifiquem com essas mulheres e suas necessidades.

\section{MÉTODO}

Tendo-se em vista a inserção da questão investigada no campo das ciências subjetivas, optou-se pela pesquisa qualitative e foram empregadas técnicas de entrevista e observação. A priori, as entrevistas tinham como objetivo coletar histórias de vida das prostitutas, o que não se concretizou pela dificuldade de acesso aos sujeitos. Observou-se que estes constituem uma população de alta rotatividade, sem compromisso de horário com os encontros marcados com a entrevistadora e que necessitam estar o tempo todo disponíveis para atender aos clientes. Decorreu disso uma mudança de estratégia, orientada para a coleta de depoimentos acerca dos acontecimentos diretamente relacionados com a gravidez e a maternidade de prostitutas. 
Segundo QUEIROZ et al. (1988:20-1) a diferença entre história de vida e depoimento está na forma específica de agir do pesquisador. Ao colher um depoimento a conversa é dirigida pelo entrevistador para a obtenção exclusivamente de informações de seu interesse, podendo esgotar-se num único encontro. Por outro lado, a história de vida se define como o relato de um narrador sobre sua existência através do tempo e geralmente encerra um conjunto de depoimentos. É uma técnica cuja aplicação demanda longo tempo.

Paralelamente, as entrevistas eram complementadas por uma observação do tipo participante, no local de moradia e trabalho das prostitutes. Foram visitados três prostíbulos situados no Bairro Dona Zulmira, na cidade de Uberlândia.

\section{Os sujeitos}

Partindo do pressuposto de que a gravidez representa uma etapa mercante e singular na história de cada mulher e que geralmente, estas conseguem descrever com detalhes as experiências vivenciadas nessa fase, mesmo que em épocas remotas, foram abordadas, além das prostitutas grávidas, prostitutas que já haviam estado grávidas.

Foram entrevistadas três prostitutas grávidas e quatro que já haviam estado grávidas. De uma maneira geral, todas aparentavam ter mais idade. Em alguns encontros trajavam-se com muito pouca roupa parecendo não se importarem em expor sua nudez. Quanto ao nível de escolaridade do grupo, variava de primeiro grau incompleto até segundo grau completo. Todas relataram ser oriundas de classe social baixa.

O quadro 1 mostra a idade e a paridade das entrevistadas.

\section{Procedimento}

Nos primeiros contatos, a entrevistadora apresentava-se como Ginecologista-Obstetra do Posto de Saúde do bairro e expunha seu interesse em orientar a população de prostitutas com relação à assuntos relacionados com saúde sexual.

$\mathrm{O}$ encontro com as prostitutas entrevistadas ocorreu nos quartos que servem ao mesmo tempo de moradia e local de trabalho para suas ocupantes. Essas reuniões aconteceram no horário entre 11:00 e 13:00 h, ocasião em que estas estavam acordando. Os depoimentos foram obtidos 
em um ou mais encontros dependendo das circunstâncias e da necessidade de informações adicionais. Eram gravados em fita cassete e transcritos para posterior análise.

A princípio, era lhes solicitado que narrassem sua história de vida e no decorrer da entrevista, o colóquio era dirigido pela entrevistadora, objetivando captar os fatos relevantes para os objetivos do presente estudo.

Os tópicos norteadores utilizados nas entrevistas foram:

1 - Dados pessoais: incluindo nome, cor, idade, escolaridade, origem situação financeira familiar, relação com os progenitores.

2 - Relatos de violência e abuso sexual na infância e adolescência (principalmente envolvendo pais ou substitutos).

3 - História sexual: idade da la relação sexual, idade em que ingressou na prostituição, motivo(s) da entrada na prostituição.

4 - Gravidez e Maternidade: paridade, motivação para engravidar idade da $1^{a}$ gravidez, percepção e reação à gravidez, interrupção voluntária ou espontânea da gestação, significado da maternidade, conhecimento e uso de métodos contraceptivos na época da ocorrência da gestação, sintomas durante a gravidez, percepção do corpo, idade gestacional em que detectou que estava grávida, sentimentos experimentados durante a gravidez, o exercício da profissão durante a gravidez, complicações obstétricas, assistência médica durante a gravidez e parto.

5 - Vínculo com o filho: Amamentação, maternagem, destino dado aos filhos, relacionamento efetivo e situação dos filhos hoje.

As entrevistas desencadearam fortes emoções nas entrevistadas, levando muitas delas a chorar. Isto, em geral acontecia quando eram abordados os assuntos referentes à infância, aos pais e aos filhos. Com o decorrer do tempo, houve o estabelecimento de um vínculo de respeito e confiança entre as participantes e a autora. No final da coleta dos depoimentos, a população investigada era convidada a comparecer em consulta ginecológica. Em decorrência disso, as três prostitutas gestantes, freqüentaram consultas de pré-natal com a autora. Destas apenas "olhos verdes", participou efetivamente do pré-natal. Sua gestação transcorreu sem intercorrências clínicas e evoluiu para cesariana devido à uma distócia de trajeto. Essa grávida demonstrou durante as consultas estar satisfeita com a gravidez e exibia um certo equilíbrio emocional. Foi acompanhada após o parto e verificou-se que confeccionava muitos planos para o futuro. $\mathrm{O}$ 
sujeito apelidado de "Fã do Renato Russo" só compareceu à uma consulta de pré-natal. A autora teve notícias de que a mesma tinha ido para Goiânia e estava procurando uma forma de interromper sua gravidez de 20 semanas. "Morena" só procurava o atendimento quando lhe era conveniente. Apresentava um grande cisto de Bartholin em sua vulva que lhe causava intenso desconforto e que constantemente demandava drenagem. Mostrou-se poliqueixosa em todas as consultas. Evoluiu para parto normal prematuro e doou seu filho para um casal. Acompanhada no puerpério parecia outra pessoa (como se o patinho feio tivesse se transformado num cisne). Estava alegre, falante, bem vestida e não mais empenhada em conseguir ser submetida à laqueadura tubária.

O procedimento utilizado para a análise dos discursos baseou-se no método interpretativo-indiciário. Tal metodologia, inspirada nos pressupostos psicanalíticos pressupõe a existência de um nível manifesto e um nível latente do discurso dos sujeitos investigados. O método indiciário, segundo GINZBURG (1987), procura através de pistas e indícios alcançar aqueles elementos que não são diretamente explicitados mas que ficam sugeridos nas entrelinhas. Na interpretação de um fato, não importa o dado bruto ou a coisa em si, mas as múltiplas possibilidades de sentido que ele encerra.

De uma primeira leitura de todo o material discursivo, alguns indícios das razões e do sentido da gravidez e maternidade de mulheres prostitutas foram emergindo e delineando aquilo que, após uma segunda leitura, configurou as categorias de análise dos discursos a saber:

- Relacionamentos com a mãe;

- Relacionamento com o pai;

- Opinião a respeito da maternidade;

- Vivência da gravidez;

- Contracepção;

- Fertilidade.

\section{CATEGORIAS DE ANÁLISE DOS DISCURSOS}

\section{Tema 1 - Relacionamento com a mãe}

Olhos verdes:

... eu gostava muito dela, todo mundo me fala que eu pareço muito com ela, que eu sou parecidíssima com ela". 
Morena:

"Minha mãe morava na zona. Ela me espancava muito quando eu nasci. Ela me batia pra eu ficar de pé. Pegava o cipó e me batia nas pernas, me xingava (anda desgraçada), e eu não conseguia andar”.

\section{Fã do Renato Russo:}

"Ela não era a mãe que eu queria".

“... não fazia nada assim, que... que mãe faz para o filho, ela nunca fazia, nem dava muita atenção".

"Eu sou a primeira gravidez dela. E ela não queria".

\section{Menina da noite:} sabe?"

... eu não sei com quem eu fui criada, era assim tipo uma bolinha,

"Não cuidou de mim, não cuidou dos outros".

\section{Crioula:}

"Meus pais adotivos. Eles me pegaram quando eu tinha um mês. Eles me pegaram no lixo".

\section{Baiana:}

"A minha mãe, eu vim vê ela de grande".

\section{Tema 2 - Relacionamento com o pai}

Olhos verdes:

“... às vezes eu tenho mágoa do meu pai, por isso. Que ele num soube segurá todo mundo junto e eu nunca mais procurei por ele" .

... a culpa é dele. Alguém tem que ser culpado pela morte dela”.

\section{Morena:}

"Ela sabia que eu não tinha pai nem mãe”.

Fã do Renato Russo:

"Meu pai fazia o papel de mãe e pai".

Garota dos bichinhos:

"Meu pai tentou me matar".

"Se eu ver ele na rua, eu corto volta dele. Não converso com ele de jeito nenhum. Eu não gosto dele. Eu odeio ele. Sabe, eu não tenho pai”.

Menina da noite:

"Eu vi o meu pai, ele tinha, eu tinha 4 anos. Nunca procurou ajudá a gente. Nunca tive ajuda nenhuma dele". 


\section{Baiana:}

"Não, meu pai, eu não sei quem é, nunca vi”.

\section{Tema 3 - Opinião a respeito da maternidade}

Olhos verdes:

“... depois não, quando eu senti, o nenê foi crescendo, sabe, parece que aquele sentimento passou pra ele".

"Ele vai ser um, tipo uma plantinha e aí você vai ter que ter cuidado demais".

\section{Morena:}

"Mas não posso criar. Agora eu não posso criar não".

"Eu tenho coragem de ganhá ele e dá pros outros. Mesmo que dói muito, mas eu prefiro dá, do que matá".

\section{Garota dos bichinhos:}

"Deixei nasce".

"Minha mãe que cria ele desde novinho".

Menina da noite:

"É a mãe dele que cuida".

"Fico no meio da rua, mas eu não dou ele. Eu vô cuidá dele, da maneira que eu der conta, mas eu não vou dá meu filho".

\section{Tema 4 - Vivência da gravidez}

Olhos verdes:

"Eu tenho medo de às vezes, no hospital de eu morrer ou dele morrer; de alguém trocá, dele... sei lá".

"Eu não suporto que ninguém fica me tocando".

Fã do Renato Russo:

"... agora assim que eu tô grávida, eu tenho muito medo".

"Não é a mesma relação. A relação não fica mais a mesma coisa também. A gente sai do quarto, é como se não existisse mais. Depois que tá grávida. Sente muita dor na barriga, depois né, dá uma sensação ruim, de peso, uma sensação tão estranha".

\section{Morena:}

... eu tomei raiva das pessoas. Nervosa, só fico chorando. Tenho nojo de tudo".

“... os homens também não querem, né. Eles preferem mulher sem barriga. Eu também não quem não. Depois eu não agüento nem andar. Fica doendo, tudo dolorido". 


\section{Tema 5 - Contracepção}

Fã do Renato Russo:

"A minha cabeça não funciona muito. Eu não me preocupo muito com esse tipo de coisa".

\section{Morena:}

"Nunca evitei. Na época eu não evitava".

"Porque é uma coisa que a gente descuida. Eu queria era ligá mesmo".

Menina da noite:

"É agora eu sou ligada, eu mandei ligá... porque eu não queria mais sofrer, sabe, tê filho, eu não queria mais".

\section{Tema 6 - Fertilidade}

Morena:

"O dia que eu fiquei eu já engravidei".

"Um dia só que aconteceu de eu transar sem camisinha, aí eu engravidei".

Fã do Renato Russo:

"Aí eu parei de tomar, foi coisa de um mês que parei de tomar, aí eu engravidei".

Olhos verdes:

"Eu fiquei esse tempo todo com meu ex-marido e nunca engravidei, não tomava remédio e num evitava de forma nenhuma".

\section{ANÁLISE DOS DEPOIMENTOS E DISCUSSÃO}

Através da análise dos discursos acerca do tema 1, observa-se que somente no caso de "olhos verdes", a mãe constituía uma figura significativa. As outras introjetaram a imagem da mãe má, que não cuida, não acolhe, só maltrata. Interessante verificar que apesar dessa prostituta ter perdido a mãe muito cedo, ela de alguma forma resguardou dela uma lembrança afetuosa. Seu depoimento é o único que deixa transparecer uma construção de amor materno no desenrolar da gestação.

$\mathrm{O}$ tema 2 denuncia dificuldades das prostitutas de relacionarem-se com seus pais. Apenas a "Fã do Renato Russo" expressa afeto pelo pai, contudo ele também morre precocemente. 
A total ausência de figuras parentais significativas poderia justificar as dificuldades da maioria do grupo no exercício das funções de maternagem, expressas no tema 3 . Elas não retêm uma imagem interna de família. A mãe prostituta sente-se impotente para criar seu filho já que não vivenciou um modelo de família para imitar. Prefere transferir suas responsabilidades de cuidadora e provedora para terceiros.

A gravidez é vivenciada por esses elementos como uma experiência de medo, pavor, pânico e revolta. Isso se justifica pela sua própria imaturidade mental. Ainda pelos discursos do tema 4, verifica-se que a gravidez incompatibiliza-se com a atividade sexual, que representa a garantia de seu sustento. O coito surge como uma experiência no mínimo desagradável. No tema 5, constata-se que a contracepção não é levada em conta seriamente. Parece existir uma idéia pré-concebida de ineficiência dos métodos contraceptivos, em especial o preservativo e o anticoncepcional hormonal oral.

Detectou-se também que algumas entrevistadas alimentavam fantasias de grande potencial de fertilização ou de esterilidade, o que poderia influenciar o não uso desses métodos.

A representação que se pode apreender do discurso de grávida/mãe/prostituta relativamente à figura materna é de uma mãe má e retaliadora. Poder-se ia dizer que a figura materna por um mecanismo de aniquilamento não se impõe na mente destas mulheres e com isso a conotação de maldade torna-se ainda maior. Em relação a figura paterna, a fala das entrevistadas demonstra que quando o pai não está ausente, ele figura como vilão.

Verifica-se ainda nos depoimentos das prostitutas, relatos de abuso sexual e violência na infância e adolescência. Os infratores foram parentes próximos ou conhecidos das vítimas.

A gravidez ou o sentido que este estado tem para estas mulheres é de um movimento compulsivo. Elas parecem apreender um mínimo de vontade consciente no movimento de engravidar. Parecem vivenciar uma situação onde o corpo se impõe e é dono absoluto da frágil mente que elas constróem. O corpo é percebido como um objeto, uma mercadoria, um instrumento de troca com o outro.

Alguns indícios mostraram que através da gravidez elas parecem buscar insanamente a reconstituição de uma figura que nunca foi efetivamente delineada: a figura materna. À medida que não dispõem de uma representação significativa desta figura, abrem mão da posse e cuidado de um filho, transferindo as incumbências maternais para qualquer pessoa mais habilitada. Em um dos encontros a autora verificou que duas das pros- 
titutas grávidas, apesar de terem seus quartos individuais, optavam por dormirem juntas e seminuas na cama de casal e esta cena reportou-lhe a lembrança de dois bebês ou mãe e bebê. Pareceu-lhe que apesar da proximidade física, a interação entre ambas era superficial no plano afetivo. Como se uma estivesse amparando a outra, movida por um processo de identificação.

A estrutura e organização da mente destas mulheres parece se configurar tal qual os estados infantis ou primitivos da mente ou seja: são poucos os seus recursos de simbolização. Elas estruturam a linguagem a nível concreto e por isso às vezes se confundem e confundem os seus circundantes com seus atos. Tal qual acontece com as crianças, mostraram-se às vezes birrentas e manipuladoras. Dão a impressão de funcionar sempre almejando algo em troca.

Parece que elas revivem continuamente alguns medos vivenciados na infância; por exemplo: medo de ir ao dentista, medo de tomar injeção, medo de ficar sozinha.

Em determinadas ocasiões observou-se uma necessidade delas de demonstrarem muita segurança, muita autoconfiança. A fragilidade de sua estrutura psíquica faz com que utilizem como mecanismo de compensação, a onipotência.

\section{CONSIDERAÇÕES FINAIS}

O presente estudo detectou uma grande dificuldade na vivência da gravidez e no exercício da maternidade de prostitutas. Compreender o significado destas dificuldades implicaria numa ponderação de todas as situações adversas que estas mulheres enfrentam no curso de suas vidas.

É preciso levar em consideração seu estado de mente infantil, incapaz de considerar toda a problemática que emerge em decorrência da gravidez e da função da maternidade.

O corpo para estas mulheres não tem o significado que tem para uma mulher que transcende a dimensão concreta do orgânico. É visto como um objeto, uma mercadoria, um instrumento de troca; o corpo grávido não condiz com esta concepção que elas têm de corpo. Talvez esse seria um dos motivos da não procura dos serviços de assistência pré-natal.

Outro ponto a ser enfatizado seria a ausência de uma estrutura familiar, o que dificulta o estabelecimento de vínculos efetivos com a prole, contribuindo para a interrupção da gravidez, abandono e doação dos filhos. 
Tendo em vista a multiplicidade de questões emergentes com o tema, fez-se necessário o empreendimento de novas pesquisas. Este estudo não teve a pretensão de esgotar o assunto, à medida em que se verificou uma complexidade de fatores envolvidos na motivação e na ação de engravidar dessas mulheres prostitutas. Pretende-se no entanto sensibilizar os profissionais de saúde que atuam junto à essa população para o desenvolvimento de modelos alternativos para a abordagem e o acompanhamento médico e psicológico dessa parcela da população. Uma primeira sugestão para quem deseja trabalhar com essas mulheres seria a de conhecer a realidade de suas vidas e o meio em que vivem, demonstrando o interesse genuíno em estabelecer um vínculo.

A autora acredita que uma maneira de captar lhes a atenção seria através da barganha, um artifício que sabidamente elas reconhecem no seu dia a dia. Parece-lhe que estes sujeitos são mais cooperativos quando sentem que estão levando alguma vantagem, mesmo que seja num ato simples de distribuição gratuita de preservativos ou anticoncepcionais orais.

Outra sugestão seria a de trabalhar de maneira lúdica para informar e educar acerca das questões relacionadas com a sexualidade, utilizando-se de simplicidade e de conceitos primários.

\section{Quadro I - Idade e paridade das prostitutas.}

\begin{tabular}{|l|c|c|c|c|}
\hline \multicolumn{1}{|c|}{ Sujeito } & Idade & $\begin{array}{c}\text { Número de } \\
\text { gestações }\end{array}$ & $\begin{array}{c}\text { Número de } \\
\text { partos }\end{array}$ & $\begin{array}{c}\text { Número de } \\
\text { abortos }\end{array}$ \\
\hline Garota dos bichinhos & 30 & 04 & 02 & 02 \\
\hline Baiana & 33 & 09 & 05 & 04 \\
\hline Fã do Renato Russo* & 21 & 03 & 01 & 01 \\
\hline Morena* & 24 & 04 & 03 & - \\
\hline Menina da noite & 23 & 02 & 01 & 01 \\
\hline Olhos verdes* & 25 & 01 & - & - \\
\hline Crioula & 26 & 03 & 03 & - \\
\hline
\end{tabular}

Fonte: elaborado pela autora.

2. O asterisco serve para destacar as prostitutas grávidas. 


\section{REFERÊNCIAS BIBLIOGRÁFICAS}

1. BEDONE, Dalva Maria Bertoni et al. Prostituição e saúde. J. bras. ginec, 97 (5): p. 201-206, 1987.

2. CAROLINO, Edna Maria de Paiva. Subsídios para o estudo dos problemas de Saúde Mental numa população de prostitutas. Ribeirão Preto: Universidade de São Paulo, Escola de Enfermagem de Ribeirão Preto, 1980. 136p. (Dissertação de Mestrado)

3. DEISHER, Robert W.; LITCHFIELD, Christina; HOPE, Kerry R. Birth out-comes of prostituting adolescents. Journal of Adolescent Health, New York, 12 (7): p. 528-533, november 1991.

4. FOUCAULT, Michael. História da sexualidade II - O uso dos prazeres. Rio de Janeiro: Graal, 1984.

5. GINZBURG, Carlo. O queijo e os vermes. São Paulo: Ed. Cia das Letras, 1987.

6. QUEIROZ, Maria Isaura Pereira. Experimentos com história de vida. (ItáliaBrasil). Enciclopédia aberta de Ciências Sociais, v. 5. São Paulo: Vértice Revista dos Tribunais, 1988. 